\title{
PENGARUH PEMANASAN TANAH DIATOME TERHADAP KEMAMPUAN ADSORPSI Cd (II) DALAM PELARUT AIR
}

\author{
Tien Setyaningtyas ${ }^{1}$ dan Sriyanti ${ }^{2}$
}

Laboratorium Kimia Anorganik Jurusan Kimia

Fakultas MIPA Universitas Diponegoro Semarang 50275

\begin{abstract}
ABSTRAK
Telah dilakukan penelitian tentang pengaruh pemanasan tanah diatome terhadap kemampuan adsorpsi logam kadmium (II) dalam pelarut air. Parameter eksperimen meliputi temperatur pemanasan, waktu kesetimbangan dan kapasitas adsorpsi. Kapasitas adsorpsi ditentukan melalui penggunaan isoterm adsorpsi Langmuir yang menekankan pembentukan lapisan monomolekuler sebagai konsekwensi interaksi kimia antara ion logam dan gugus aktif adsorben. Peranan gugus siloksan dipelajari dengan membandingkan perilaku adsorpsi ion logam pada permukaan tanah diatome dengan jumlah relatif gugus siloksan yang berbeda. Secara eksperimen langkah ini dilakukan dengan menggunakan sistem "batch shaker".

Hasil eksperimen menunjukkan bahwa pemanasan tanah diatome mempengaruhi jumlah gugus siloksan. Jumlah gugus siloksan bertambah dengan naiknya temperatur pemanasan tanah diatome dan menurunkan kapasitas adsorpsi kadmiun (II). Temperatur pemanasan tanah diatome pada $100^{\circ} \mathrm{C}$ mempunyai kapasitas adsorpsi paling besar yaitu $39,34 \mathrm{mg} / \mathrm{g}$. Kapasitas adsorpsi kadmium (II) pada tanah diatome alam dan pada pemanasan $500{ }^{\circ} \mathrm{C}, 900{ }^{\circ} \mathrm{C}$ masing-masing adalah $29,22 \mathrm{mg} / \mathrm{g}$; $23,18 \mathrm{mg} / \mathrm{g} ; 12,3 \mathrm{mg} / \mathrm{g}$.
\end{abstract}

Kata kunci : adsorpsi, tanah diatome, temperatur pemanasan, gugus siloksan

\section{EFFECT HEATING OF DIATOMACEOUS EARTH OF ADSORPTION CAPACITY Cd (II) IN AQUEOUS SOLUTION}

\begin{abstract}
Effect heating of diatomaceous earth of adsorption capacity metal ion cadmium (II) in aqueous solution has been investigated. Experimental parameter studied included temperature heating, time equilibrium and adsorption capacity.

The adsorption capacity was determined based on the Langmuir adsorption isotherm model emphasizing the formation of monomolecular layer due to chemical interaction between the metal ion and the active site of adsorbent. The role of siloxan group was evaluated by comparing the adsorption behavior of metal ion on diatomaceous earth surface having different relative number of siloxan group. Experimentally, all steps were performed in a series of experiment utilizing a batch shaker system

The results showed that heating of diatomaceous earth is influence number siloxan group. Account number siloxan group is increase with increasing temperature heating of diatomaceous earth and decreasing of adsorption capacity metal ion cadmium (II). Temperature heating of diatomaceous earth on $100^{\circ} \mathrm{C}$ has the greatest adsorption capacity is $39,34 \mathrm{mg} / \mathrm{g}$. The Adsorption capacity of $29,22 \mathrm{mg} / \mathrm{g} ; 23,18 \mathrm{mg} / \mathrm{g} ; 12,3 \mathrm{mg} / \mathrm{g}$ which were respectively observed for natural diatomaceous earth and at temperature heating of $500{ }^{\circ} \mathrm{C} ; 900^{\circ} \mathrm{C}$.
\end{abstract}

Key words : adsorption, diatomaceous earth, temperature heating, siloxan group

1. Program Sarjana MIPA Universitas Jenderal Soedirman

2. Fakultas MIPA-KIMIA Universitas Diponegoro

\section{PENDAHULUAN}

Metoda pengambilan logam dari buangan limbah industri telah banyak dilakukan, antara lain dengan metoda pengapuran yaitu cara pengendapan logam berat sebagai hidroksidanya. Metoda pengendapan memang praktis tetapi hasilnya kurang memuaskan karena tidak mampu menghilangkan ion logam dari larutan, bila konsentrasi logam sangat kecil. Alternatif lain melalui elektrodeposisi, namun cara ini untuk beberapa logam tidak dapat memberi hasil yang memuaskan terutama untuk $\mathrm{Pb}, \mathrm{Cd}$, dan $\mathrm{Hg}$. Selain itu proses elektrodeposisi membutuhkan monitoring dan peralatan yang tidak murah. Oleh karena itu para peneliti mulai memusatkan perhatian pada metoda adsorpsi untuk pengambilan ion logam dari perairan tercemar dan limbah buangan industri (Willard,1974).

Metoda adsorpsi merupakan metoda pengolahan air limbah yang lebih unggul dibandingkan dengan 
metoda lain. Keuntungan utama sistem adsorpsi adalah biaya murah, tidak ada efek samping zat beracun, serta mampu menghilangkan bahan-bahan organik dibandingkan perlakukan secara biologi yang konvensional (Gupta dkk, 1988). Beberapa penelitian tentang adsorpsi telah banyak dilakukan, baik yang mengkaji bahan yang mungkin dapat digunakan sebagai adsorben maupun kajian mengenai faktor-faktor yang mempengaruhi adsorpsi.

Bahan adsorben yang sering digunakan adalah karbon aktif, silika gel, zeolit, tanah diatome. Mellah dan Chegrouche (1997) menggunakan bentonit alam untuk menyerap seng $(\mathrm{Zn})$ dalam pelarut air. Hasil yang diperoleh bahwa penyerapan seng pada bentonit alam dipengaruhi oleh ukuran partikel, temperatur, kecepatan adsorpsi dan konsentrasi seng dalam pelarut air. Penelitian tentang kemungkinan tanah diatome sebagai adsorben telah banyak dilakukan, sedangkan pengaruh dari pemanasan tanah diatome belum dikaji secara mendalam. Pada penelitian ini digunakan tanah diatome sebagai adsorben karena selain mudah diperoleh dan harga relatif murah, tanah diatome juga merupakan material berpori dan kaya akan silika yang diperkirakan berperan dalam proses adsorpsi.

Beberapa penelitian menunjukkan bahwa komponen utama tanah diatome adalah silika yang tersusun atas satuan-satuan tetrahedron. Menurut Clark (1960), Kirk cian Othmer (1979), silika sebagai komponen utama tanah diatome adalah amorf $\left(\mathrm{SiO}_{2} \mathrm{nH}_{2} \mathrm{O}\right)$, dimana atom-atom silikon dan oksigen dalam silika tersusun secara tetrahedron mirip dengan silika kristal tetapi jaringan tersebut tidak terulang secara periodik dan simetri seperti halnya dalam kristal. Tanah diatome diketahui mengandung zat-zat organik dan oksidaoksida logam yang diduga mengganggu kemampuan adsorpsi ion logam. Proses pemanasan akan menurunkan kadar zat-zat organik dan oksida-oksida logam selain $\mathrm{SiO}_{2}$ sehingga kadar $\mathrm{SiO}_{2}$ makin dominan. Kemampuan adsorpsi tanah diatome dipengaruhi oleh adanya gugus siloksan (Si-O-Si) dan gugus silanol ( $\mathrm{Si}-\mathrm{OH})$.

Pengaruh pemanasan tanah pada umumnya menunjukkan kehilangan massa mulai pada suhu $150^{\circ}-180^{\circ} \mathrm{C}$ yang diperkirakan merupakan pengaruh hidroskopik ataupun campuran pengotor hidroskopik dengan bahan organik yang bersifat volatil. Bahan- bahan organik yang terdapat dalam tanah secara umum mulai terdekomposisi pada suhu $210^{\circ}-240^{\circ} \mathrm{C}$ dan secara sempurna terdekomposisi pada suhu $500^{\circ} \mathrm{C}$ (Wendlandt, 1986)

Untuk membuktikan peranan gugus siloksan dan silanol terhadap kemampuan adsorpsi tanah diatome, maka digunakan ion logam kadmium (II). Hal ini disebabkan perbedaan sifat asam-basa lunak dan keras menurut prinsip Hard and soft acid-base (HSAB), ion kadmium (II) merupakan asam lunak sedangkan gugus siloksan (Si-O-Si) maupun gugus silanol ( $\mathrm{Si}-\mathrm{OH})$ berifat basa keras. Jadi semakin banyak gugus siloksannya ( $\mathrm{Si}-\mathrm{O}-\mathrm{Si}$ ) akan menurunkan kapasitas adsorpsi $\mathrm{Cd}(\mathrm{II})$. Banyaknya gugus siloksan ini dipengaruhi oleh kadar silikat $\left(\mathrm{SiO}_{2}\right)$ dalam tanah diatome, sehingga semakin besar kadar silkat $\left(\mathrm{SiO}_{2}\right)$ dalam tanah diatome maka gugus siloksannya juga akan semakin banyak

\section{METODA PENELITIAN}

Alat-alat yang digunakan berupa saringan 100 mesh, pengguncang, oven, furnace, spektrofotometer serapan atom Hitachi Z-8000, spektrofotometer UV-Visibel Hitachi 250-20 dan peralatan gelas.

Tanah diatome yang digunakan dalam penelitian ini berasal dari Sangiran, dusun Pabringan, Kelurahan Kerikilan. Kecamatan Kalijambi, Kabupaten Sragen, Jawa Tengah. Bahan penelitian lainnya adalah $\mathrm{CdCl}_{2} \cdot \mathrm{H}_{2} \mathrm{O}$ (E. Merck), $\mathrm{NaOH}$ (E.Merk)

Jalan penelitian meliputi penggerusan dan pengayakan tanah diatome dengan ukuran 100 mesh, selanjutnya dilakukan pemanasan pada $100^{\circ} \mathrm{C}, 500^{\circ} \mathrm{C}$, dan $900^{\circ} \mathrm{C}$, masing-masing selama 5 jam. Tanah diatome hasil pemanasan masing-masing ditentukan kadar $\mathrm{SiO}_{2}$ serta $\mathrm{Al}_{2} \mathrm{O}_{3}$ menggunakan spektrofotometer UVVis yang sebelumnya dilebur menggunakan $\mathrm{NaOH}$. Untuk mengetahui peranan dari gugus siloksan dan silanolnya, tanah diatome digunakan sebagai adsorben ion logam kadmium (II) dan adsorpsi dilakukan dengan sistem "batch shaker".

Penggunaan tanah diatome sebagai adsorben mulamula menentukan waktu kesetimbangan adsorpsi. Sebanyak 0,1 gram adsorben masing-masing dimasukkan ke dalam botol pengguncang kemudian ditambahkan larutan $\mathrm{Cd}(\mathrm{II})$ dengan konsentrasi $100 \mathrm{ppm}$, waktu kontaknya masing-masing $5,10,20,30$, dan 
60 menit, konsentrasi kesetimbangan $\mathrm{Cd}$ dianalisis dengan spektrometer serapan atom.

Kapasitas adsorpsi tanah diatome alam dilakukan dengan memasukkan 0,1 gram adsorben masing-masing ke dalam botol penggucang kemudian dimasukkan larutan $\mathrm{Cd}$ (II) masing-masing dengan konsentrasi 5, 10, $20,50,100,500,1000$ ppm. Konsentrasi kesetimbangan $\mathrm{Cd}$ dianalisis dengan spektrometer serapan atom. Hasil yang diperoleh merupakan selisih konsentrasi mula-mula dengan konsentrasi setelah teradsorpsi. Hal ini juga dilakukan untuk tanah diatome yang dipanaskan pada $100^{\circ} \mathrm{C}, 500^{\circ} \mathrm{C}$ dan $900^{\circ} \mathrm{C}$. Kapasitas adsorpsi ditentukan dengan persamaan Langmuir :

$\frac{c}{m}=\frac{1}{b K}+\frac{1}{b} c$

dimana $\mathrm{c}$ adalah konsentrasi kesetimbangan, $\mathrm{m}$ adalah jumlah zat yang teradsorpsi per gram adsorben, $b$ adalah kapasitas adsorpsi maksimum dan $\mathrm{K}$ adalah tetapan. Bila data yang diperoleh memenuhi persamaan tersebut di atas, maka plot $\mathrm{c} / \mathrm{m}$ terhadap c akan menghasilkan garis lurus dengan slope $1 / \mathrm{b}$ dan intersep 1/bK

\section{HASIL DAN PEMBAHASAN}

Komponen utama tanah diatome alam adalah silikat $\left(\mathrm{SiO}_{2}\right)$ dan oksida-oksida logam lainnya seperti Aluminium oksida $\left(\mathrm{Al}_{2} \mathrm{O}_{3}\right)$, selain itu mengandung zatzat organik. Pemanasan tanah diatome pada suhu $100^{\circ} \mathrm{C}, 500^{\circ} \mathrm{C}$ dan $900^{\circ} \mathrm{C}$ meningkatkan kadar $\mathrm{SiO}_{2}$ dan menurunkan kadar $\mathrm{Al}_{2} \mathrm{O}_{3}$, seperti terlihat pada tabel 1 .

Tabel 1. Pengaruh pemanasan tanah diatome terhadap kadar $\mathrm{SiO}_{2}$ dan $\mathrm{Al}_{2} \mathrm{O}_{3}$

\begin{tabular}{|l|c|c|}
\hline \multirow{2}{*}{ Tanah diatome } & \multicolumn{2}{|c|}{ Kadar $(\%$ berat) } \\
\cline { 2 - 3 } & $\mathbf{S i O}_{\mathbf{2}}$ & $\mathbf{A l}_{\mathbf{2}} \mathbf{O}_{\mathbf{3}}$ \\
\hline Tanah diatome alam & 64,55 & 15,88 \\
Pemanasan $100^{\circ} \mathrm{C}$ & 66,17 & 14,32 \\
Pemanasan $500^{\circ} \mathrm{C}$ & 85,96 & 4,25 \\
Pemanasan $900^{\circ} \mathrm{C}$ & 89,64 & 1,77 \\
\hline
\end{tabular}

Kenaikan kadar $\mathrm{SiO}_{2}$ dan penurunan $\mathrm{Al}_{2} \mathrm{O}_{3}$ belum menunjukkan perubahan yang signifikan pada pemanasan $100^{\circ} \mathrm{C}$. Hal ini disebabkan pada pemanasan $100^{\circ} \mathrm{C}$ hanya menurunkan kadar air, sedangkan oksida-oksida logam belum mengalami dekomposisi begitu juga untuk zat-zat organik yang terkandung dalam tanah diatome. Kenaikan kadar $\mathrm{SiO}_{2}$ dan penurunan kadar $\mathrm{Al}_{2} \mathrm{O}_{3}$ terlihat signifikan pada pemanasan $500^{\circ} \mathrm{C}$, karena pada temperatur $500^{\circ} \mathrm{C}$ kandungan zat-zat organik sudah terdekomposisi sedangkan pengotor oksida-oksida logam hanya sebagian yang terdekomposisi, sedangkan pemanasan pada temperatur $900^{\circ} \mathrm{C}$ tidak dimungkinkan lagi adanya senyawa-senyawa organik, dan oksida logam pengotor sebagian besar sudah terdekomposisi. Kandungan air juga sangat kecil begitu juga gugus silanolnya sudah berkurang sehingga akan meningkatkan gugus siloksan.

Penggunaan tanah diatome sebagai adsorben untuk logam kadmium (II) mula-mula ditentukan waktu kesetimbangan adsorpsinya, dengan memvariasi waktu kontak. Waktu kesetimbangan adsorpsi ditunjukkan pada gambar 1 .

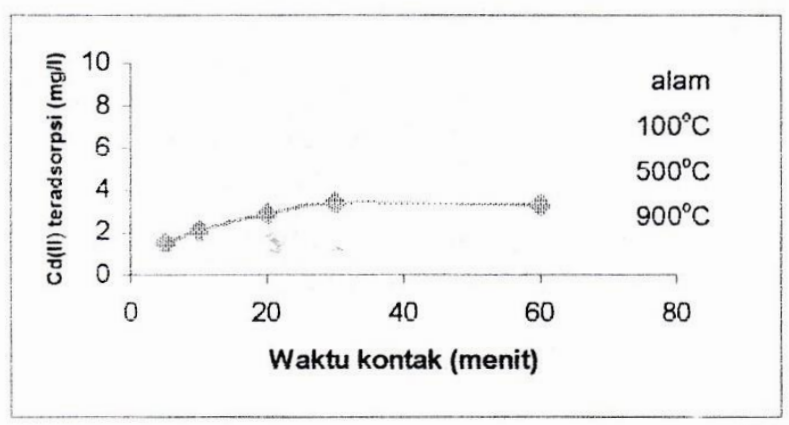

Gambar 1. Pengaruh waktu kontak terhadap Cd(II) teradsorpsi

Dari gambar 1 dapat disimpulkan bahwa waktu kesetimbangan adsorpsi tercapai pada 20 menit. Sehingga adsorpsi selanjutnya dilakukan sampai waktu kesetimbangan tercapai .

Kapasitas adsorpsi Cd (II) pada tanah diatome dapat dilihat pada tabel 2. Kapasitas paling besar terjadi pada pemanasan tanah diatome $100^{\circ} \mathrm{C}$ yaitu $39,34 \mathrm{mg} / \mathrm{g}$ sedangkan yang paling sedikit pada pemanasan $900^{\circ} \mathrm{C}$ yaitu $12,3 \mathrm{mg} / \mathrm{g}$. Hal ini dikarenakan pada temperatur $100^{\circ} \mathrm{C}$ masih terdapat senyawa-senyawa organik yang dimungkinkan terlibat dalam proses penyerapan sehingga akan membentuk suatu ikatan antara logam dengan senyawa organik (ikatan organologam). Selain itu kadar $\mathrm{SiO}_{2}$ belum meningkat, sehingga dari teori hard and soft acid base (HSAB) pengaruh dari gugus siloksan ( $\mathrm{Si}-\mathrm{O}-\mathrm{Si})$ dan silanol $(\mathrm{Si}-\mathrm{OH})$ yang bersifat basa keras belum menunjukkan sifat yang berarti.

Tanah diatome alam mempunyai kapasitas adsorpsi lebih besar dibandingkan dengan tanah diatome yang dipanaskan pada $500^{\circ} \mathrm{C}$ dan $900^{\circ} \mathrm{C}$. Hal ini disebabkan tanah diatome alam masih mengandung senyawa- 
senyawa organik yang dapat membentuk ikatan organologam dan masih banyak mengandung air Kandungan air yang cukup tinggi menyebabkan tanah diatome alam mempunyai kapasitas adsorpsi $\mathrm{Cd}(\mathrm{II})$ lebih rendah daripada tanah diatome yang dipanaskan pada $100^{\circ} \mathrm{C}$. Pemanasan tanah diatome pada temperatur $100^{\circ} \mathrm{C}$ akan memutuskan ikatan hidrogen antara air dengan gugus silanol atau antara air dengan gugus siloksan, sehingga kandungan airnya menjadi lebih sedikit

Tabel 2. Kapasitas adsorpsi Cd (II)

\begin{tabular}{|l|c|}
\hline \multicolumn{1}{|c|}{ Adsorben } & $\begin{array}{c}\text { Kapasitas adsorpsi Cd(II) } \\
(\mathbf{m g} / \mathbf{g})\end{array}$ \\
\hline Tanah diatome alam & 29,22 \\
Pemanasan $100^{\circ} \mathrm{C}$ & 39,34 \\
Pemanasan $500^{\circ} \mathrm{C}$ & 23,18 \\
Pemanasan $900^{\circ} \mathrm{C}$ & 12,3 \\
\hline
\end{tabular}

Menurut Iller (1991) ikatan hidrogen antara air dengan gugus silanol dan siloksan ditunjukkan pada gambar 2 , sedangkan ikatan ion logam dengan gugus siloksan dan silanol ditunjukkan seperti pada gambar 3 .<smiles>O[SiH2]O[SiH2]OPO</smiles>

Gambar 2. Ikatan hidrogen air dengan gugus siloksan dan silanol

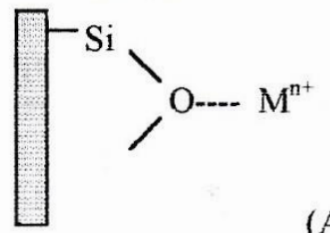

(A)

$\mathrm{SiOH}+\mathrm{M}^{\mathrm{n}+} \longrightarrow \mathrm{SiOM}^{(\mathrm{n}-1)+}+\mathrm{H}^{+}$

(B)

Gambar 3.

A. ikatan gugus siloksan dengan ion logam.

B. ikatan gugus silanol dengan ion logam

$\mathrm{M}^{\mathrm{n}+}$ sebagai ion logam.

Pemanasan tanah diatome pada $500^{\circ} \mathrm{C}$ dan $900^{\circ} \mathrm{C}$ kapasitas adsorpsinya semakin kecil,karena menurut teori HSAB gugus siloksan (Si-O-Si) merupakan basa keras sedangkan ion kadmium (II) merupakan asam lu-nak sehingga semakin banyak kadar silikatnya $\left(\mathrm{SiO}_{2}\right)$ akan menurunkan kapasitas adsorpsi Cd (II). Kapasitas adsorpsi pada tanah diatome alam dan pemanasan $500^{\circ} \mathrm{C} ; 900^{\circ} \mathrm{C}$ berturut-turut adalah $29,22 \mathrm{mg} / \mathrm{g}$; $23,18 \mathrm{mg} / \mathrm{g}$ dan $12,3 \mathrm{mg} / \mathrm{g}$. Grafik adsorpsi isoterm Langmuir ditunjukkan pada gambar 4.

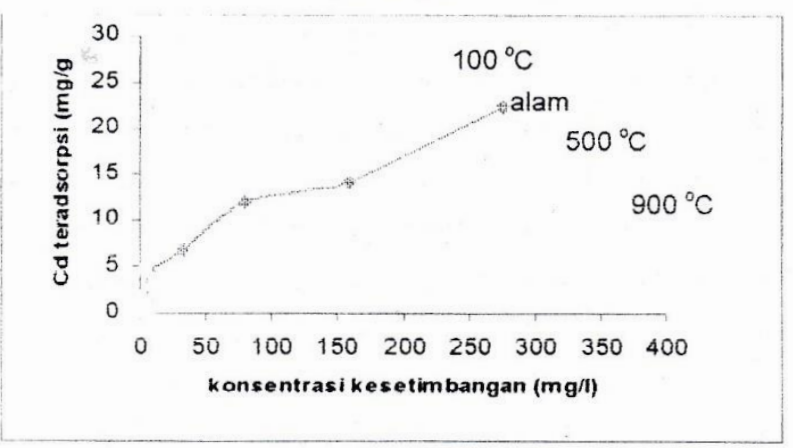

Gambar 4. Adsorpsi isoterm Langmuir Cd(II)

\section{KESIMPULAN}

1. Pemanasan tanah diatome pada temperatur $900^{\circ} \mathrm{C}$ akan menaikkan kadar silikat $\left(\mathrm{SiO}_{2}\right)$ sebesar $38,87 \%$ dan menurunkan kadar alumunium oksida $\left(\mathrm{Al}_{2} \mathrm{O}_{3}\right)$ sebesar $88,85 \%$

2. Semakin banyak kadar silikat pada tanah diatome akan menurunkan kapasitas adsorpsi ion logam kadmium (II)

3. Pemanasan tanah diatome pada $100^{\circ} \mathrm{C}$ mempunyai kapasitas adsorpsi paling besar yaitu $39,43 \mathrm{mg} / \mathrm{g}$, sedangkan kapasitas adsorpsi tanah diatome alam, dan pada pemanasan $500^{\circ} \mathrm{C}$; $900^{\circ} \mathrm{C}$ berturutturut adalah $29,22 \mathrm{mg} / \mathrm{g} ; 23,18 \mathrm{mg} / \mathrm{g} ; 12,3 \mathrm{mg} / \mathrm{g}$.

\section{DAFTAR PUSTAKA}

1. Clark,G.L., 1960, "Encyclopedia of Chemistry," Reinhold Publishing Corporation, New York

2. Gupta, G.S., Prassad, G., Panday,K.K., and Singh, V.N.,1988, "Removal of Chrom

3. Dyes from Aqueous Solution by Fly Ash", J. Water, Air ana Soil Pollution, 32,384-395

4. Iller,R.K.,1991, "Silica Chemistry in Natural and Industry," J.Physical Chemistry, 95, 4063-4069

5. Kirk and Othmer, 1979, "Encyclopedia of Chemical Technology," fifth edition, John Wiley and Sons, New York

6. Mellah, A., and Chegrouche, S., 1997, "The Removal of Zinc From Aqueous Solutions by Natural Bentonit", Wat Res, Vol 31, 621-629

7. Wendlandt, W.W.M., 1986, "Thermal Analysis", John Wiley and Sons,USA

8. Willard, H.B., Merrit, Jr., Dean, J.A., 1974, "Instrumentai Methods of Analysis," $4^{\text {th }}$ ed, Van Nostrand Reinhold, New York 